\title{
Fine mapping of X-linked clasped thumb and mental retardation (MASA syndrome) in Xq28
}

Legius E, Kaepernick L, Higgins JV, Glover TW. Fine mapping of Xlinked clasped thumb and mental retardation (MASA syndrome) in $\mathrm{Xq} 28$.

Clin Genet 1994: 45: 165-168. (C) Munksgaard, 1994

The MASA syndrome is an X-linked disorder with mental retardation, spastic paraparesis, and adducted thumbs as the most characteristic features. We performed linkage analysis, using Xq28 markers, on a large MASA syndrome family. The maximum lodscore was 6.37 at 0 recombination for DXS52 and 5.99 at 0 recombination for DXS305. Crossovers were demonstrated between the disorder and DXS455. Clinical and linkage data from this family further support the hypothesis that the MASA syndrome and X-linked hydrocephalus are allelic disorders.

\section{E. Legius',2, L. Kaepernick', J. V. Higgins ${ }^{3}$ and T. W. Glover}

'University of Michigan, Department of Pediatric Genetics, Ann Arbor, Michigan, USA, ${ }^{2}$ Centre for Human Genetics, Leuven, Belgium, and ${ }^{3}$ Michigan State University, Department of Pediatrics, USA

Key words: carrier detection - HSAS - L1CAM - linkage analysis - MASA syndrome $X$-linked hydrocephalus

Dr. E. Legius, Centre for Human Genetics, Herestraat 49, B-3000 Leuven, Belgium

Received 25 March, revised version received 20 September, accepted for publication 14 December 1993
The MASA syndrome and X-linked hydrocephalus (HSAS) have both been linked to markers in Xq28 (Kenwrick et al. 1986, Winter et al. 1989, Schrander-Stumpel et al. 1990, Rietschel et al. 1991, Macias et al. 1992, Willems et al. 1990 and 1992). In both disorders adducted thumbs, spastic paraparesis, mental retardation and variable degrees of hydrocephalus can be observed. Moreover, within the same family some patients may have the MASA syndrome phenotype, while others clearly display an X-linked hydrocephalus phenotype (SchranderStumpel et al. 1990, Fryns et al. 1991). Carrier females can also show features such as mild mental retardation and adducted thumbs (Macias et al.1992). Here we report linkage analysis with markers in Xq28 in a large family with the MASA syndrome/X-linked hydrocephalus.

\section{Materials and methods}

\section{Patients}

Peripheral blood samples were taken from 49 individuals from a large family (Fig. 1), including seven obligate carrier females and 13 affected males, some with the MASA syndrome, and some with features identical to HSAS (individuals 40, 75, 84). An extensive clinical description of this family is reported in an accompanying paper (Kaepernick et al., this issue).

DNA analysis

DNA was extracted from peripheral white blood cells, using a whole blood lysis procedure, followed by a salt-chloroform extraction procedure (Mullenbach et al. 1989). Eight micrograms of DNA were digested with the appropriate restriction enzymes, separated on $1 \%$ agarose gels by electrophoresis and blotted onto Hybond $\mathrm{N}+$ nylon membranes (Amersham) by alkaline transfer, as recommended by the supplier. Membranes were hybridized with ${ }^{32} \mathrm{P}$ oligolabelled probes to detect polymorphisms in Xq28. Probes used in these experiments are listed in Table 1 . In addition to these probes, a CA repeat in F8C was tested by PCR (Lalloz et al. 1991). Fluorescein isothiocyanate (FITC) was conjugated to one of the PCR primers, and PCR products were separated on an automatic sequencing device (ALF, Pharmacia).

\section{Linkage analysis}

Patients with the MASA syndrome phenotype as well as those with HSAS phenotype were classified 


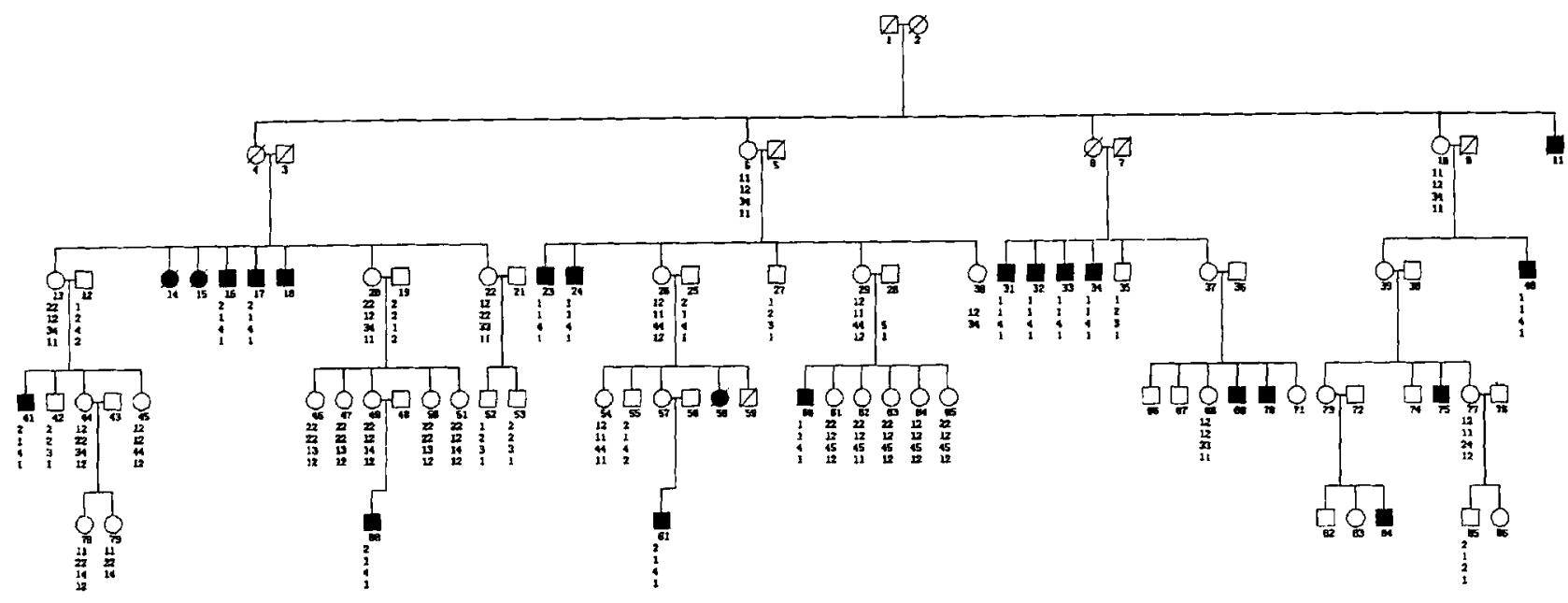

Fig. 1. Pedigree of the MASA syndrome family, showing individuals from whom blood was obtained for linkage analysis and carrier detection. Individuals are numbered from top to bottom and from left to right. Alleles are listed as haplotypes in the following order: DXS455, DXS305, DXS52 and DXS15 (Willems et al. 1992). A crossover is observed between the MASA syndrome and DXS455 when transmitted from individual 2 to individual 4. A similar crossover occurred between individuals 26 and 81 . In individuals 62 and 64, a crossover occurred between DXS455 and DXS15 when receiving the markers from their mother (individual 29).

as affected for the purpose of linkage analysis. Penetrance for affected males was 1; for heterozygote females a penetrance of 0 was used, although some females expressed minor symptoms (Kaepernick et al., this issue). A disease frequency of 0.0001 was assumed for the disorder.

Unaffected males younger than 5 years old were not included in the analysis.

Two-point linkage analysis between marker locus and disease locus was carried out using the Mlink computer program from the Linkage programs (Lathrop et al. 1985). The same program was used for 3-point risk calculations to determine the carrier status in female relatives. Multipoint lodscores were calculated using the Linkmap subprogram. The pedigree in Fig. 1 was drawn with the PEDRAW program (Curtis 1990).

\section{Results}

Polymorphisms tested in the $\mathrm{F} 8 \mathrm{C}$ region were not informative or were only partly informative, in-

Table 1. The probes used in the linkage experiments are shown in the putative order from centromere to telomere (DXS303 to F8C)

\begin{tabular}{lcccc}
\hline Locus & Probe & RFLP & Alleles & PIC \\
\hline DXS304 & U6.2 & Taql & 2 & 0.31 \\
DXS455 & 346.6 & Taql & 2 & 0.50 \\
DXS305 & St35-691 & Taql & 2 & 0.46 \\
DXS52 & St14-1 & Taql & 8 & 0.85 \\
DXS15 & DX13 & Bglil & 2 & 0.47 \\
F8C & p114.12 & Bcll & 2 & 0.41 \\
& p482.6 & Xbal/Kpnl & 2 & 0.37 \\
\hline
\end{tabular}

cluding the $\mathrm{CA}$ repeat in the $\mathrm{F} 8 \mathrm{C}$ gene. The same was true for DXS304. Probes for DXS455, DXS305 and DXS52 proved to be very informative in this family. Two crossovers were observed between the disease and DXS455. A crossover must have occurred between DXS455 and the MASA syndrome in individual 4 , since all the affected male descendants carry allele 2 , whereas the affected males elsewhere in the pedigree carry allele 1 , except for individual 81 . No crossovers were observed between the MASA syndrome and markers DXS52 and DXS305, resulting in a maximum two-point lodscore of 6.37 for DXS52 at 0 recombination, and 5.99 for DXS305 at 0 recombination (Table 2). These figures prove that the syndrome in this family is definitely linked to markers DXS52 and DXS305 in Xq28. DXS15 was only partly informative but proved to be helpful in assigning or excluding carrier status in several females. The gene for X-linked hydrocephalus is localized between DXS52 and F8C (Willems et al. 1992, Rosenthal et al. 1992). The distance between these two markers is about $2 \mathrm{cM}$.

Table 2. Two-point lodscores between MASA syndrome and different loci at different recombination fractions

\begin{tabular}{lcrrrrrrr}
\hline & \multicolumn{9}{c}{ Lodscore at theta of } & & \multicolumn{2}{c}{ Theta } \\
\cline { 2 - 6 } Locus & 0 & 0.01 & 0.05 & 0.10 & 0.20 & Z max & max \\
\hline DXS304 & 0.455 & 0.445 & 0.406 & 0.358 & 0.265 & 0.455 & 0 \\
OXS455 & $-\infty$ & -0.598 & 0.601 & 0.949 & 0.812 & 1.043 & 0.16 \\
DXS305 & 5.997 & 5.901 & 5.509 & 4.999 & 3.903 & 5.997 & 0 \\
DXS52 & 6.373 & 6.268 & 5.847 & 5.302 & 4.139 & 6.372 & 0 \\
\hline
\end{tabular}


A recent report by Rosenthal et al. suggests that mutations in the LICAM gene are responsible for the MASA syndrome. If we assume the MASA syndrome and X-linked hydrocephalus are both caused by a mutation in LICAM, we can place the MASA syndrome locus at 3\% recombination telomeric to DXS52. By doing so, we could exclude carrier status in 11 females with more than $96 \%$ certainty (individuals $30,44,46,47,50,61,63,64$, 65,78 and 79) and in one with more than $94 \%$ certainty (individual 77). On the other hand, carrier status could be assigned to four women with more than $96 \%$ certainty (individuals $45,51,54$ and 62).

Multipoint lodscore calculations were performed using data from reported families (SchranderStumpel et al. 1990, Fryns et al. 1991), combined with data from the family in this report. DXS455, DXS304, DXS52 and F8C were placed in this order in a fixed position with respective distances of $0.5 \mathrm{cM}$ (DXS455, DXS304), $3.5 \mathrm{cM}$ (DXS304, DXS52) and $2 \mathrm{cM}$ (DXS52, F8C) (Willems et al. 1992). The locus for the MASA syndrome was variable. A maximum multipoint lodscore of 9.03 was obtained for the MASA syndrome at DXS52, with DXS455 and F8C as flanking markers. DXS455 is localized on the centromeric side of DXS52 and F8C on the telomeric side. The 95\% confidence limits with the lodscore minus one technique is $2.8 \mathrm{cM}$ proximal and $2 \mathrm{cM}$ distal of DXS52.

The respective odds for placing the MASA syndrome centromeric to DXS455 between DXS455 and DXS304, and telomeric of F8C versus between DXS304 and F8C are respectively 22.9:1, 66:1 and $69: 1$.

\section{Discussion}

In this large family, the MASA syndrome/X-linked hydrocephalus segregates with loci in Xq28. The maximum two-point lodscore between the disorder and DXS52 is 6.37 at 0 recombination. Linkage to DXS52 has been reported previously in families with MASA syndrome (Kenwrick et al. 1986, Winter et al. 1989, Schrander-Stumpel et al. 1990, Fryns et al. 1991, Macias et al. 1992). However, this is the largest single family for which linkage data are available. Including the family reported here, the combined maximum two-point lodscore between the MASA syndrome and DXS52 is 15.4 at 0 recombination (Kenwrick et al. 1986, Winter et al. 1989, Schrander-Stumpel et al. 1990, Fryns et al. 1991, Mascias et al. 1992). In all reported pedigrees, no recombination has been observed between the MASA syndrome and DXS52, and only one recombination with $\mathrm{F} 8 \mathrm{C}$ has been reported (Schrander-Stumpel et al. 1990). Here we report a recombination between the MASA syndrome and DXS455. This marker is localized on the centromeric side of DXS52. These two recombination events, one with F8C and one with DXS455, place the MASA syndrome between DXS455 and F8C. Multipoint analysis with Linkmap using data from some reported families (Schrander-Stumpel et al. 1990, Fryns et al. 1991) and the family reported here places the syndrome at DXS52, between DXS455 and F8C, with a maximum multipoint lodscore of 9.03 . The information on the localization of the MASA syndrome can be used for carrier detection in female relatives, as was done in this report. More accurate carrier prediction as well as prenatal diagnosis will be possible in nearly every female at risk if the molecular defect in MASA syndrome is discovered.

Multipoint analysis of HSAS families places the gene for this disorder between DXS52 and F8C, with neural cell adhesion molecule Ll (L1CAM) as a candidate gene (Willems et al. 1992). In a recent report, a point mutation in LICAM has been reported in affected individuals in an HSAS family (Rosenthal et al. 1992). This point mutation is localized in an intron and interferes with mRNA splicing. Since HSAS and the MASA syndromes have been localized to the same subchromosomal region, and HSAS and the MASA syndromes can be present in the same families showing linkage to the same markers, it is very likely that in these families both disorders are the result of a mutation in the same gene. However, these data do not exclude the possibility of a second gene in Xq28 responsible for HSAS or the MASA syndrome in other families.

\section{Acknowledgements}

This work was supported by a research fellowship from the D. Collen Research Foundation of Belgium (EL).

\section{References}

Curtis D. A program to draw pedigrees using LINKAGE or LINKSYS data files. Ann Hum Genet 1990: 54: 365-367.

Fryns J-P, Spaepen A, Cassiman JJ, Van Den Berghe H. X linked complicated spastic paraplegia, MASA syndrome, and $X$ linked hydrocephalus owing to congenital stenosis of the aqueduct of Silvius: variable expression of the same mutation at Xq28. J Med Genet 1991: 28: 429-431.

Kaepernick L, Legius E, Higgins J, Kapur S. Clinical aspects of the MASA syndrome in a large family, including expressing females. Clin Genet 1994: 45: 181-185.

Kenwrick S, Ionasescu V, Ionasescu G, Searby C, King A, Dubovitz M, Davies KE. Linkage studies of X-linked recessive spastic paraplegia using DNA studies. Hum Genet 1986: 73: 264-266.

Lalloz MRA, McVey JH, Pattinson JK, Tuddenham EGD. Haemophilia A diagnosis by analysis of a hypervariable dinucleotide repeat within the factor VIII gene. Lancet 1991: 338: 207-211. 


\section{Legius et al.}

Lathrop M, Lalouel J-M, Ott J. Multilocus linkage analysis in humans: detection of linkage and estimation of recombination. Am J Hum Genet 1985: 37: 482-498.

Macias VR, Day DW, King TE, Wilson GN. Clasped-thumb mental retardation (MASA) syndrome: confirmation of linkage to Xq28. Am J Med Genet 1992: 43: 408-414.

Mullenbach R, Lagoda PJL, Welter C. An efficient salt-chloroform extraction of DNA from blood and tissues. TIG 1989:84: 35-40.

Rietschel M, Friedl W, Uhlhaas S, Neugebauer M, Heimann D, Zerres K. MASA syndrome: clinical variability and linkage analysis. Am J Med Genet 1991: 41: 10-14.

Rosenthal A, Jouet M, Kenwrick S. Aberrant splicing of neural cell adhesion molecule LI mRNA in a family with X-linked hydrocephalus. Nature Genet 1992: 2: 107-112.

Schrander-Strumpel C, Legius E, Fryns JP, Cassiman JJ. MASA syndrome: new clinical features and linkage analysis using DNA probes. J Med Genet 1990: 27: 688-692.

Willems PJ, Dijkstra I, Van der Auwera BJ, Vits L, Coucke P, Raeymaekers $P$, Van Broeckhoven C, Consalez GG, Freeman SB, Warren ST, Brouwer OF, Brunner HG, Renier WO, Van Elsen AF, Dumon JE. Assignment of X-linked hydrocephalus to Xq28 by linkage analysis. Genomics 1990: 8: 367-370.

Willems PJ, Vits L, Raeymaekers P, Beuten J, Coucke P, Holden JJA, Van Broeckhoven C, Warren ST, Sagi M, Robinson D, Dennis N, Friedman KJ, Magnay D, Lyonnet S, White BN, Wittwer BH, Aylsworth AS, Reicke S. Further localization of $\mathrm{X}$-linked hydrocephalus in the chromosomal region Xq28. Am J Hum Genet 1992: 51: 307-315.

Winter RM, Davies KE, Bell MV, Huson SM, Patterson MN. MASA syndrome: further clinical delineation and chromosomal localisation. Hum Genet 1989: 82: 367-370. 